\title{
Editorial
}

\section{Impaired Response to Immunotherapy in Non-Alcoholic Steatohepatitis-Related Hepatocellular Carcinoma?}

\author{
Masatoshi Kudo \\ Department of Gastroenterology and Hepatology, Kindai University Faculty of Medicine, Osaka-Sayama, Japan
}

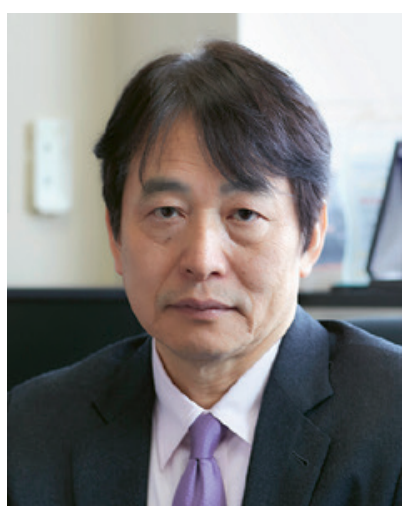

Prof. M. Kudo

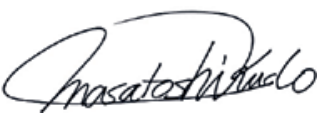

Editor Liver Cancer

\section{Keywords}

Non-alcoholic fatty liver disease $\cdot$ Non-alcoholic steatohepatitis · Hepatocellular carcinoma .

Immunotherapy · Immune checkpoint inhibitor

\section{Impaired Response to Immunotherapy in Non- Alcoholic Steatohepatitis-Related Hepatocellular Carcinoma}

An article entitled "NASH Limits Antitumour Surveillance in Immunotherapy-Treated HCC" was recently published in Nature [1]. This article presented shocking evidence that immune checkpoint inhibitors are ineffec-

karger@karger.com www.karger.com/lic

Karger $\stackrel{\text { ' }}{5}$

GOPEN ACCESS
C 2021 The Author(s)

Published by S. Karger AG, Basel

This is an Open Access article licensed under the Creative Commons Attribution-NonCommercial-4.0 International License (CC BY-NC) (http://www.karger.com/Services/OpenAccessLicense), applicable to the online version of the article only. Usage and distribution for commercial purposes requires written permission. tive in non-alcoholic steatohepatitis (NASH)-related hepatocellular carcinoma (HCC) [1]. When antitumor immunity functions normally, $\mathrm{CD}^{+}{ }^{+} \mathrm{T}$ cells are activated and become cytotoxic T lymphocytes (CTLs) upon recognition of antigens presented by major histocompatibility complex (MHC) class I molecules. Those CTLs recognize cancer antigens on the surface of cancer cells through T cell receptors and attack the cancer (Fig. 1). The study in Nature showed that mice fed a choline-deficient highfat diet or Western-style diet with trans-fat to induce NASH (NASH mice) accumulated a higher number of $\mathrm{CD}^{+} \mathrm{T}$ cells (particularly activated $\mathrm{CD} 8^{+} \mathrm{T}$ cells) over time than control mice fed a normal diet. In addition, although treatment with anti-PD-1 antibody caused a greater increase in these $\mathrm{CD} 8^{+} \mathrm{T}$ cells, particularly activated $\mathrm{CD} 8^{+} \mathrm{T}$ cells $\left(\mathrm{CD} 8^{+} \mathrm{PD}-1^{+} \mathrm{T}\right.$ cells), than in untreated controls, the treatment did not reduce the number or size of tumors in NASH-related HCC [1].

\section{Activated CD8 ${ }^{+}$T Cells Lack Immune Surveillance and Immune Responses to Cancer in NASH}

This study of NASH mice also showed that prophylactic treatment with anti-PD-1/PD-L1 antibody increases the number of activated $\mathrm{CD} 8^{+} \mathrm{T}$ cells as well as the rate of hepatocarcinogenesis, and that anti-PD-1/PD-L1 anti- 
Fig. 1. Immune response in cancer. $\mathrm{CD}^{+} \mathrm{T}$ cells are activated and become CTLs upon recognition of cancer antigens presented by MHC class I on dendritic cells. CTLs recognize cancer antigens on the surface of cancer cells through T cell receptors and attack the cancer. TCR, T cell receptor; MHC, major histocompatibility complex; TAA, tumor-associated antigen; DC, dendritic cell. Modified from Abbas et al. [20].

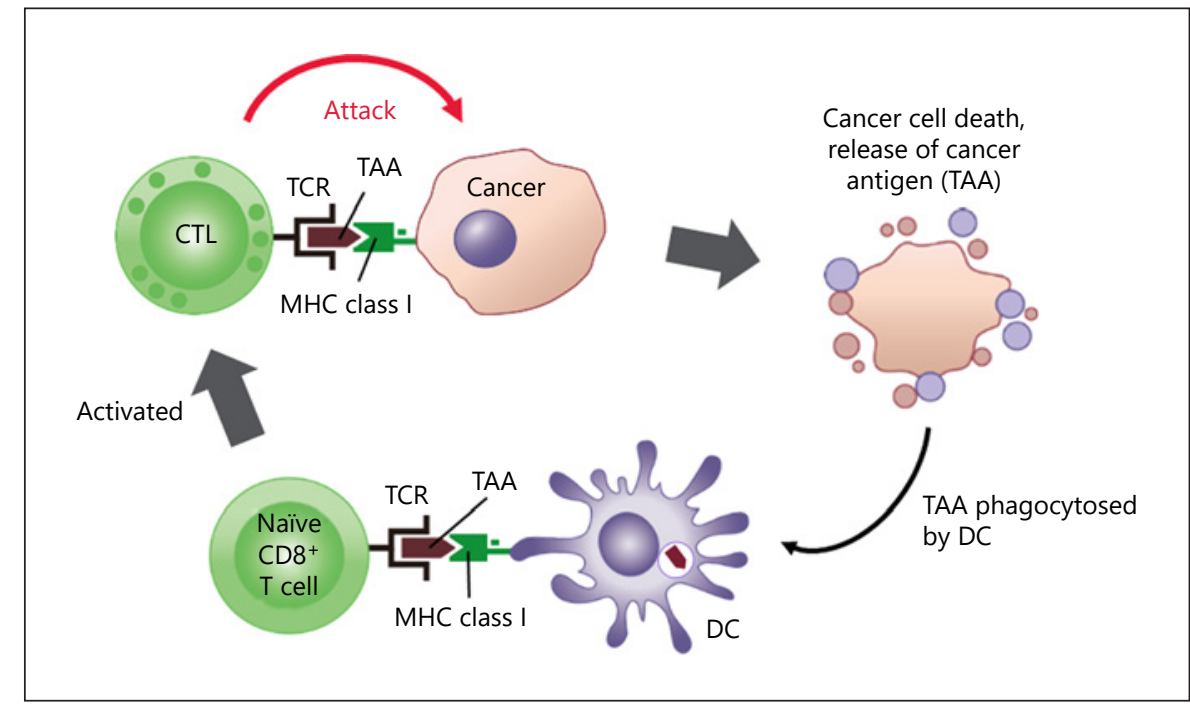

body treatment does not reduce tumor size on MRI in mice that had already developed HCC. Anti-PD-1 antibody extends survival in non-NASH models of HCC carcinogenesis, suggesting that this weakened effect of antiPD-1/PD-L1 antibody is a phenomenon specific to NASH-related HCC. The study also showed that depletion of $\mathrm{CD}^{+} \mathrm{T}$ cells by anti-CD8 antibody reduces the incidence of $\mathrm{HCC}$ and attenuates the increase in the incidence of HCC caused by anti-PD- 1 antibody. These findings support that activation of $\mathrm{CD} 8^{+} \mathrm{T}$ cells in NASH promotes carcinogenesis in NASH-related HCC. The same increase in activated $\mathrm{CD}^{+}{ }^{+} \mathrm{T}$ cells occurs through a single-cell RNA sequencing in human HCC, and is positively correlated with activation markers such as TOX and Pdcd1 (PD-1) in mice and humans. Expression of genes that serve as activation markers (exhausted markers) has also been observed in humans, indicating that a similar phenomenon may occur in human HCCs.

One explanation for the increased incidence of HCC in NASH could be that in the absence of NASH the immune surveillance mechanism triggered by $\mathrm{CD}^{+} \mathrm{T}$ cells allows $\mathrm{CD} 8^{+} \mathrm{T}$ cells, which are constantly being presented with antigens in the immune elimination phase, to function in the elimination of cancer cells [2], whereas this function is missing in activated $\mathrm{CD}^{+} \mathrm{T}$ cells in NASH (Fig. 2, 3). Authors clearly showed intratumoral activated $\mathrm{T}$ cells are $\mathrm{CXCR} 6^{+} \mathrm{CD} 8^{+} \mathrm{T}$ cells by in situ hybridization (extended data Fig. 2m, $\mathrm{n}$ in Pfister et al. [1]). Therefore, even in the immune escape phase, the number of activated $T$ cells that do not recognize antigens increases, which presumably would render treatment with anti-PD-1 antibody ineffective (Fig. 2,3). The authors also showed that depletion of $\mathrm{CD} 8^{+} \mathrm{T}$ cells reduces hepatocyte damage and fibrosis induced by treating mice with anti-PD-1 antibody (Fig. 2). They showed that the hepatocyte damage, fibrosis, and reduced antitumor immunity that occur in NASH are attributable to the special resident-like activated $\mathrm{CD}^{+}$cells expressed in NASH [1].

Inada et al. [3] showed that patients with NASH-related HCC have poor immune responses to 16 tumor antigenic peptides. They detected immune responses to these peptides in $68.8 \%$ of 32 patients with hepatitis $\mathrm{B}$ virus (HBV)-HCC, $76.2 \%$ of 42 patients with hepatitis $\mathrm{C}$ virus (HCV)-HCC, and $33.3 \%$ of 18 patients with NASH-HCC, demonstrating that the immune response to tumor antigens is reduced in NASH-HCC [3]. These data support the findings on the same topic in the Nature article.

\section{Meta-Analysis of Three Phase III Clinical Trials}

Clinical evidence supports the authors' findings. In several large phase III trials, namely the CheckMate 459 trial [4], KEYNOTE-240 trial [5], and IMbrave150 trial [6], the overall survival (OS) hazard ratio (HR) in immunotherapy-treated patients was worse for HCC of nonviral etiology than for that of viral etiology (e.g., HBV or $\mathrm{HCV}$; non-viral OS HR $=0.92$, HCV-HCC OS HR $=0.68$, HBV OS HR $=0.64$ ). A meta-analysis limited to the two first-line trials that used sorafenib as the comparator (CheckMate 459 trial and IMbrave150 trial) showed the same trend (non-viral OS HR $=0.94, \mathrm{HBV}$ OS HR $=0.65$, HCV OS HR $=0.60)$. 


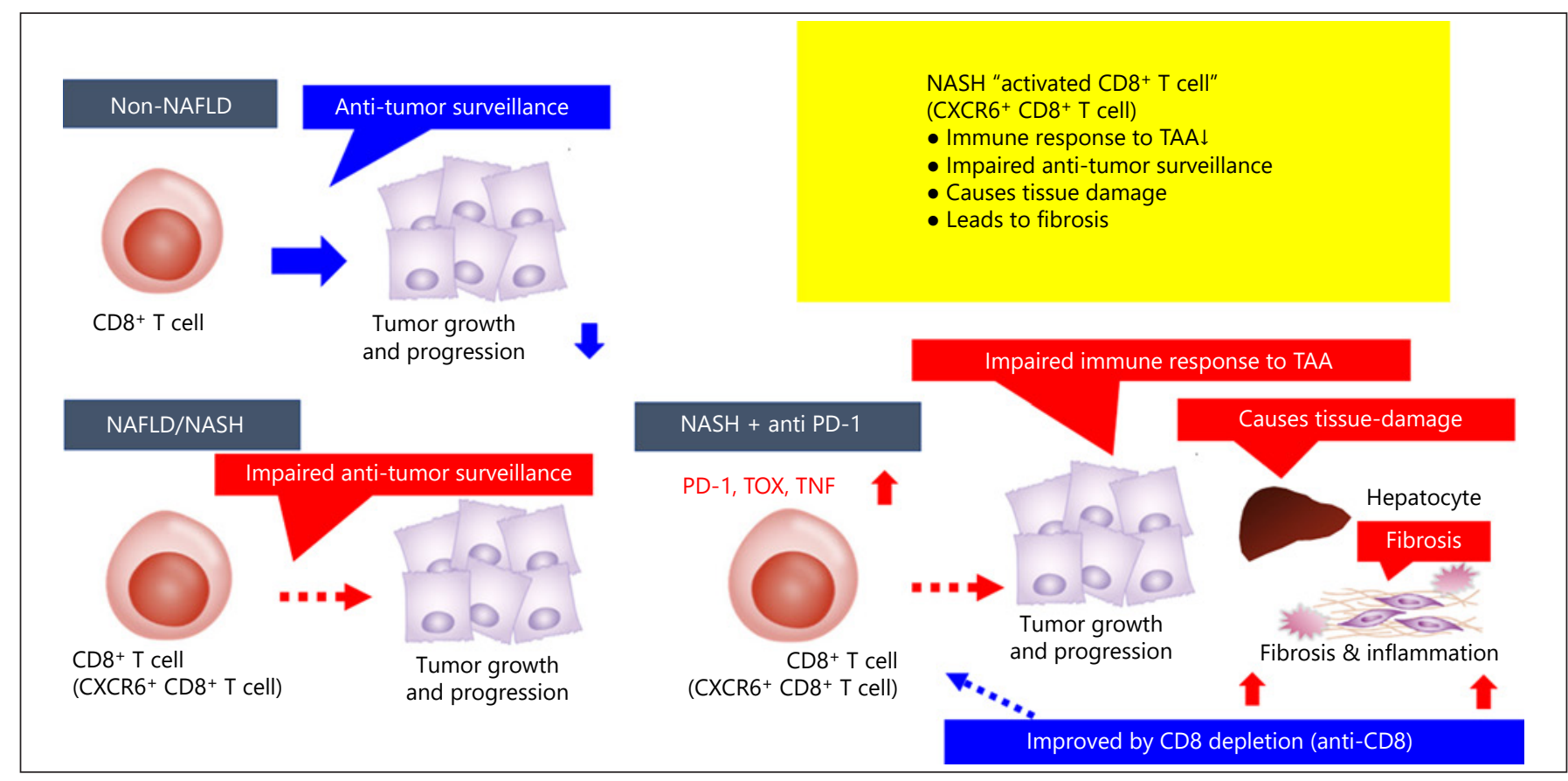

Fig. 2. Immune surveillance and antitumor response are impaired/ lacking in $\mathrm{CD}^{+}{ }^{+} \mathrm{T}$ cells $\left(\mathrm{CXCR} 6^{+} \mathrm{CD}^{+} \mathrm{T}\right.$ cell) in mouse models of NAFLD/NASH and NAFLD/NASH-related HCC. NAFLD, non-

alcoholic fatty liver disease; NASH, non-alcoholic steatohepatitis; HCC, hepatocellular carcinoma.

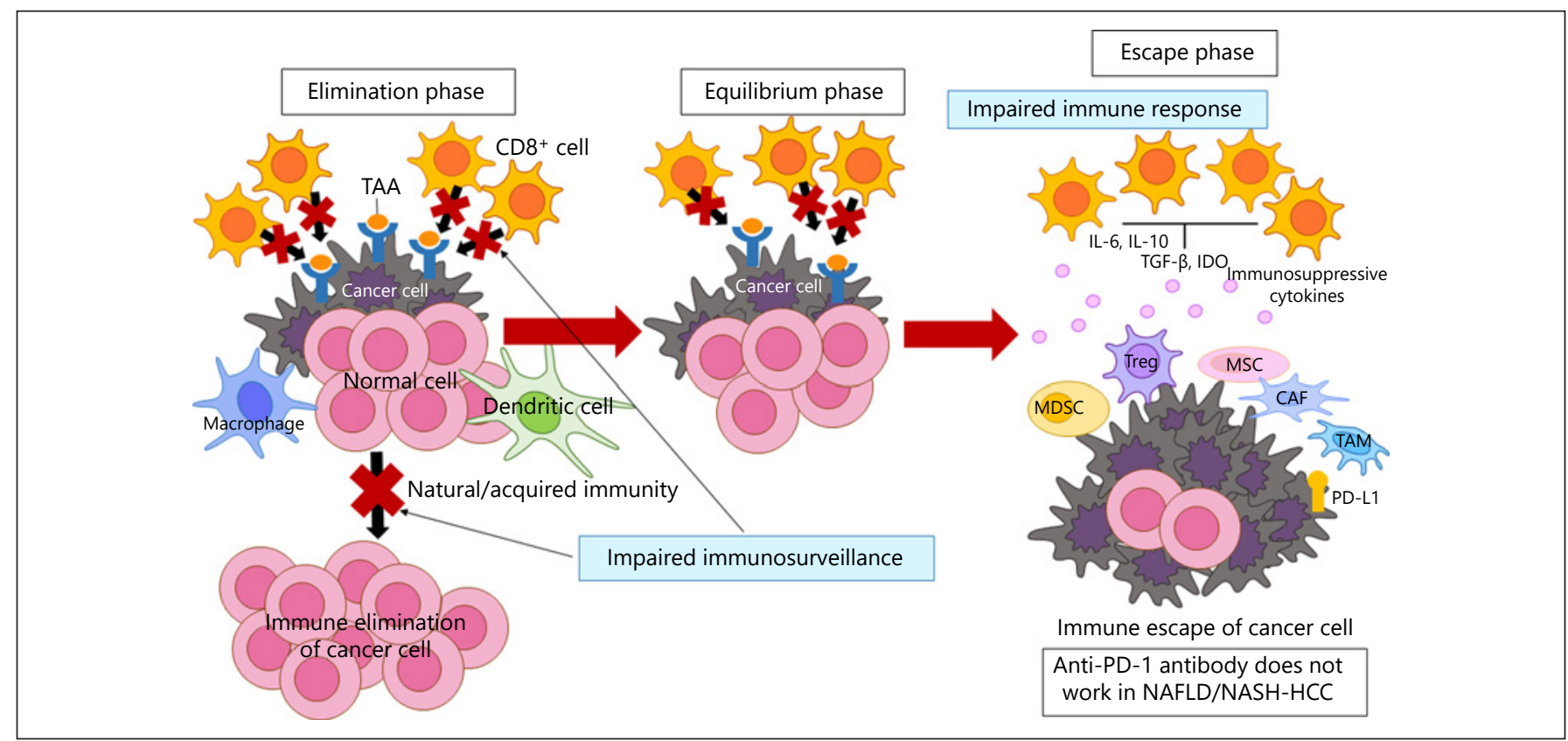

Fig. 3. Cancer immunosurveillance (cancer immunoediting) is impaired in NAFLD/NASH-HCC. In NASH-HCC, CD8 ${ }^{+} \mathrm{PD}-1^{+} \mathrm{T}$ cells are not activated in a classical manner, i.e., activation via antigen presentation by MHC class I. Therefore, in the immune elimination phase, the $\mathrm{CD} 8^{+} \mathrm{PD}-1^{+} \mathrm{T}$ cell $\left(\mathrm{CXCR} 6^{+} \mathrm{CD}^{+} \mathrm{T}\right.$ cell $)$ cannot eliminate the cancer cell since this $\mathrm{CD}^{+} \mathrm{T}$ cell cannot recognize the cancer antigen. Similarly, in the escape phase, since immune escape is not related to the PD-1/PD-L1 binding mechanism, the anti-PD-1 antibody is theoretically not effective for restoring anticancer T cell activity. TAA, tumor-associated antigen; MHC, major histocompatibility complex; MDSC, myeloid-derived suppressor cell; Treg, regulatory T cells; MSC, mesenchymal stem cell; TAM, tumor-associated macrophage; CAF, cancer-associated fibroblast. 
Table 1. OS results for two validation cohorts: NAFLD-HCC versus non-NAFLD-HCC

\begin{tabular}{|c|c|c|c|c|c|c|}
\hline & \multicolumn{2}{|c|}{ Cohort $1(n=130)$} & \multirow[t]{2}{*}{$p$ value } & \multicolumn{2}{|c|}{ Cohort $2(n=118)$} & \multirow[t]{2}{*}{$p$ value } \\
\hline & $\begin{array}{l}\text { NAFLD-HCC } \\
(n=13)\end{array}$ & $\begin{array}{l}\text { Non-NAFLD-HCC } \\
(n=117)\end{array}$ & & $\begin{array}{l}\text { NAFLD-HCC } \\
(n=11)\end{array}$ & $\begin{array}{l}\text { Non-NAFLD-HCC } \\
(n=107)\end{array}$ & \\
\hline OS, months (95\% CI) & $5.4(1.8-9.0)$ & $11.0(7.5-14.5)$ & 0.023 & $8.8(3.6-12.4)$ & $17.7(8.8-26.5)$ & 0.034 \\
\hline Country & \multicolumn{3}{|c|}{ Australia, Germany, Italy, Switzerland } & \multicolumn{3}{|c|}{ USA, Europe, Taiwan, Japan } \\
\hline Mean age, years & $72.5 \pm 8.5$ & $67.4 \pm 8.6$ & 0.046 & $67.3 \pm 7.5$ & $61.9 \pm 10.1$ & 0.046 \\
\hline Child-Pugh Class A, $n(\%)$ & $6(46)$ & $76(65)$ & 0.229 & $11(100)$ & $107(100)$ & \\
\hline Child-Pugh Class B, $n(\%)$ & $7(54)$ & $41(35)$ & & $0(0)$ & $0(0)$ & \\
\hline MVI, $n(\%)$ & $3(23)$ & $57(49)$ & 0.079 & $4(36)$ & $30(28)$ & 0.441 \\
\hline EHS, $n(\%)$ & $10(77)$ & $78(67)$ & 0.547 & $6(54)$ & $43(40)$ & 0.233 \\
\hline
\end{tabular}

EHS, extrahepatic spread; MVI, macrovascular invasion; NAFLD, non-alcoholic fatty liver disease; NASH, non-alcoholic steatohepatitis; OS, overall survival. Modified from Pfister et al. [1].

Unlike the above analysis, two validation cohorts of realworld patients restricted to non-alcoholic fatty liver disease (NAFLD)/NASH-HCC confirmed the results obtained in the NASH-HCC mouse model. In the 130 patients in the first validation cohort, the median OS was 5.4 months for NAFLD-related HCC versus 11.0 months for HCC of nonNAFLD etiology; in the 118 patients in the other validation cohort, these figures were 8.8 months versus 17.7 months. These findings indicate that treatment outcomes for antiPD-1/PD-L1 antibody are poor in NAFLD-related HCC (Table 1). Multivariate analysis also identified NAFLD-related etiology as a significant prognostic factor based on its HR of 2.6 (95\% CI 1.2-5.6, $p=0.017$ ) [1]. The facts uncovered in this Nature article pose a serious problem for clinical practice in light of projections that the prevalence of NAFLD will rapidly increase worldwide [7].

\section{$\mathrm{CD8}^{+} \mathrm{T}$ Cells in NASH Promote Hepatocyte Cell Death}

Regarding the mechanism of liver injury in NASH, Wolf et al. [8] reported that NKT cells accumulating in NASH primarily cause steatosis via secreted LIGHT, while NKT cells and $\mathrm{CD}^{+} \mathrm{T}$ cells cooperatively contribute liver damage and hepatocarcinogenesis in a NASH mouse model, demonstrating that a distinct molecular mechanism determines NASH and HCC development.

The same group published another more detailed study of the mechanism by which $\mathrm{CD} 8^{+} \mathrm{T}$ cells are activated in a mouse model of NASH in the same issue of Nature [9]. They concluded that the $\mathrm{CD}^{+} \mathrm{T}$ cells that increase unconventionally in NASH mice are resident-like
$\mathrm{CXCR}^{+} \mathrm{CD}^{+} \mathrm{T}$ cells. The underlying mechanism starts when $\mathrm{CXCR}^{+} \mathrm{CD}^{+} \mathrm{T}$ cells are activated via the suppression of FOXO1 expression by IL-15. These activated $\mathrm{CD}^{+} \mathrm{T}$ cells differ from conventional $\mathrm{CD} 8^{+} \mathrm{T}$ cells, which are activated by recognition of antigens presented by MHC class I (Fig. 1). These CXCR6 ${ }^{+} \mathrm{CD} 8^{+} \mathrm{T}$ cells react with acetate released by hepatocytes with steatosis and secrete tumor necrosis factor (TNF), and this TNF injures hepatocytes. TNF also induces ICAM-1 expression in hepatocytes and injures hepatocytes by causing the adhesion of activated $\mathrm{CD} 8^{+} \mathrm{T}$ cells to hepatocytes. In addition, induced CXCR $6^{+} \mathrm{CD} 8^{+} \mathrm{T}$ cells cause hepatocyte cell death through Fas ligand (FasL)-dependent apoptosis [9] (Fig. 4). Flow cytometry experiments performed by these authors showed that of all the interleukins tested, only stimulation by IL- 15 causes $\mathrm{CXCR} 6^{+} \mathrm{CD}^{+} \mathrm{T}$ cell proliferation, and IL-15 reduces FOXO1 expression. They also found that the level of FOXO1 expression is inversely correlated with the number of $\mathrm{CXCR} 6^{+} \mathrm{CD} 8^{+} \mathrm{T}$ cells. In essence, they confirmed through various experiments that decreased FOXO1 expression activates CXCR6 ${ }^{+} \mathrm{CD} 8^{+} \mathrm{T}$ cells. They also confirmed that TNF injures hepatocytes by showing that interaction of acetate derived from fatty acids in NAFLD with CXCR6 ${ }^{+} \mathrm{CD}^{+} \mathrm{T}$ cells injures hepatocytes; that auto-aggression increases in the presence of acetate and $\mathrm{CXCR} 6^{+} \mathrm{CD} 8^{+} \mathrm{T}$ cells; and that the NAFLD activity score and alanine aminotransferase decrease when TNF is blocked by anti-TNF antibody.

The authors also showed that $\mathrm{CXCR}^{+} \mathrm{CD}^{+} \mathrm{T}$ cells induce hepatocyte cell death through FasL-dependent apoptosis. This was supported by evidence showing that treatment with anti-FasL antibody decreases 
Fig. 4. Activation process of $\mathrm{CD} 8^{+} \mathrm{T}$ cells (CXCR6 ${ }^{+} \mathrm{PD}-1^{\text {high }} \mathrm{FOXO1}{ }^{\text {low }} \mathrm{CD}^{+} \mathrm{T}$ cell) and the mechanism of hepatocyte cell death in NAFLD/NASH patients.

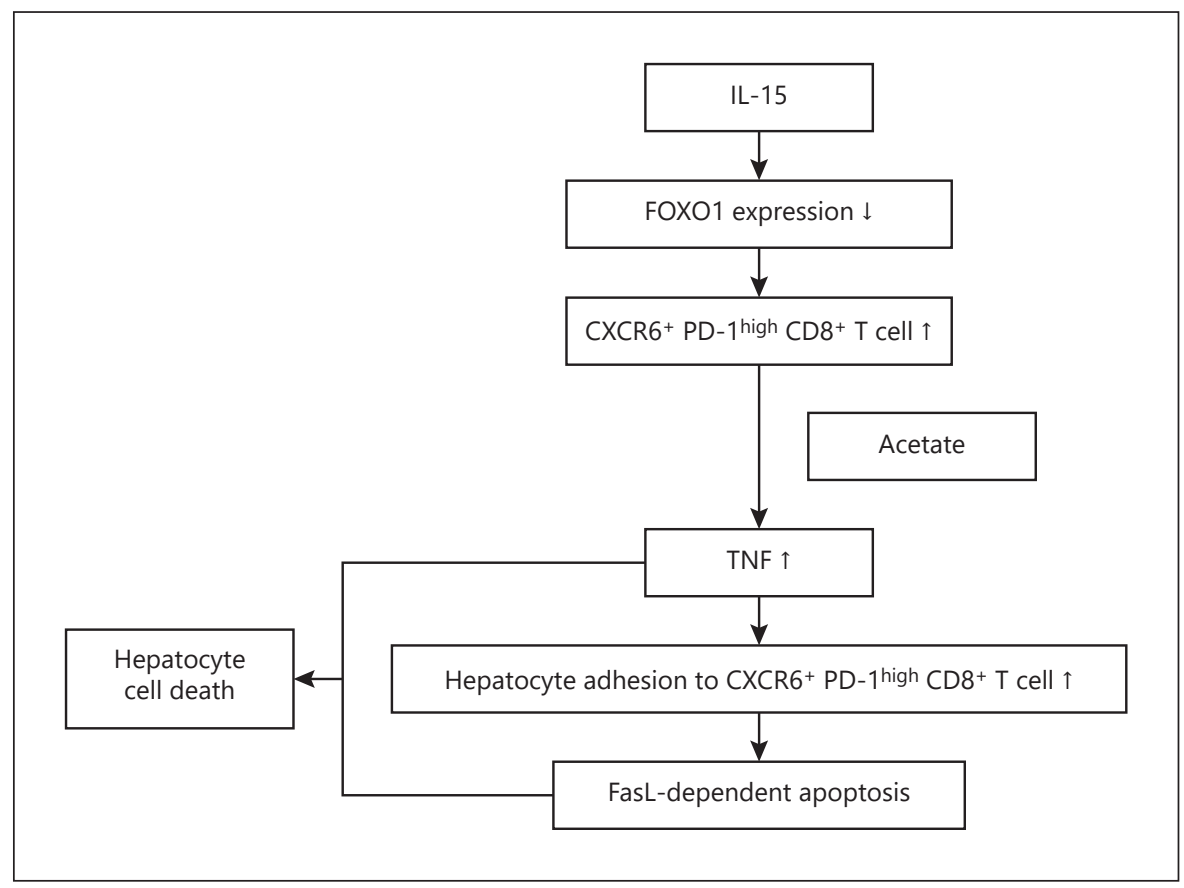

$\mathrm{CXCR}^{+} \mathrm{CD}^{+} \mathrm{T}$ cell-induced hepatocyte death and caspase activity, thereby demonstrating that apoptosis is the main cause of hepatocyte injury in NASH. Consequently, they clarified that activated $\mathrm{CD}^{+} \mathrm{T}$ cells expressed in $\mathrm{NASH}$ are unlike antigen-specific $\mathrm{T}$ cells. In addition, they showed that CXCR6 ${ }^{+} \mathrm{FOXO}^{\text {low }}$-activated $\mathrm{CD}^{+}{ }^{+} \mathrm{T}$ cells induced during NAFLD/NASH progression trigger auto-aggression in NASH, and that the process is initiated by increased IL-15 in the liver due to NAFLD (Fig. 4).

In summary, treatment of NASH mice with anti-PD-1 antibody increases the number of $\mathrm{PD}-1^{+} \mathrm{CD} 8^{+} \mathrm{T}$ cells, although this does not produce an antitumor effect. The $\mathrm{CD}^{+} \mathrm{T}$ cells that increase in the livers of NASH mice after treatment with anti-PD-1 antibody are resident-like CD $8^{+} \mathrm{PD}-1^{+} \mathrm{T}$ cells (CXCR6 ${ }^{+} \mathrm{T}$ cells). Induction of hepatocyte cell death by these $\mathrm{CXCR} 6^{+} \mathrm{CD}^{+} \mathrm{T}$ cells is activated by a completely different mechanism from the MHC class I-dependent mechanism of antigen-specific T cells, which involves activation by IL-15 and acetate, ultimately inducing apoptosis in the liver parenchyma and killing hepatocytes (Fig. 4).

\section{Mechanism of NAFLD-Related HCC Development}

The weakening of immune response and immune surveillance functions discussed in the Nature article is another important factor involved in the development of

Response of Immunotherapy in NASH-

HCC
NAFLD-related HCC, in addition to various causative factors of NASH-HCC that have been proposed to date, including genetic and epigenetic mechanisms, the microbiome, metabolic pathways, molecular signaling pathways, endocrine pathways, and immunological pathways $[8,10-13]$. In patients with NAFLD, HCC develops not only from cirrhosis [14], but also from even mild fibrosis at a rate of 25-50\% [15-19], which does not occur in viral HCC. This could explain why sorafenib yielded a better prognosis in non-viral HCC (OS 18.1 months) than in viral HCC (OS in HBV-and HCV-HCC 12.4 and 12.6 months) in the IMbrave150 trial. In other words, sorafenib and subsequent therapy might have been effective to prolong OS in non-viral HCC, especially in NAFLD-HCC, where liver function is well preserved.

\section{Unsolved Questions to Be Addressed in Immunotherapy for NASH-HCC}

The Nature study does not clarify why NASH mice are more likely to develop HCC when treated with anti-PD-1 antibody, nor the mechanism by which activated $\mathrm{CXCR}^{+} \mathrm{CD}^{+} \mathrm{T}$ cells promote carcinogenesis. These questions should be addressed in future research.

In addition, the study leaves a somewhat misleading impression that immunotherapy is not effective for all 
non-viral HCC etiologies by comparing OS HRs for nonviral HCC with those for HBV-HCC and HCV-HCC. The HRs in the IMbrave150 trial were 0.58 for HBVHCC and 0.43 for HCV-HCC versus 1.05 for non-viral HCC, which at first glance suggests that atezolizumab plus bevacizumab is less effective against non-viral HCC than viral HCC. However, the actual OS data reflect a different reality. OS after atezolizumab plus bevacizumab therapy was comparable between non-viral HCC and HBV-HCC (17.0 vs. 19.0 months, respectively). Thus, it is appropriate to conclude that atezolizumab plus bevacizumab is reasonably effective against non-viral HCC as a whole. However, sorafenib yielded markedly better OS for non-viral HCC than for HBV-HCC or HCV-HCC (18.1 vs. 12.4 and 12.6 months). This explains why the OS HR was better for sorafenib. Factors that could explain the good prognosis of patients with non-viral HCC treated with molecular targeted agents (and subsequent therapies) are that HCC often develops at the stage of NAFLD when fibrosis is minimal [15-19], as discussed earlier in this editorial, and that many patients with non-viral HCC, especially NAFLD-HCC, have favorable characteristics. In addition, the category of non-viral HCC includes non-NAFLD etiologies such as alcoholic cirrhosis, $\mathrm{AIH}, \mathrm{PBC}$, and cryptogenic cirrhosis. It is incorrect to conclude that immunotherapy is ineffective for all forms of non-viral HCC just because this Nature study showed that ICI monotherapy is ineffective in a NAFLDHCC model. Furthermore, at present it is unclear whether impaired immune surveillance in the NASH liver is reversible after the resolution of NASH. In the case of burnout NASH, it is presumed that intrahepatic resident-like $\mathrm{CXCR}^{+}{ }^{+} \mathrm{CD}^{+}{ }^{+} \mathrm{T}$ cells still exist. However, to answer these questions, real-world data need to be collected before drawing conclusions about the effectiveness of atezolizumab plus bevacizumab or other such combination immunotherapies for NASH-HCC, because most patients in the validation cohorts in the $\mathrm{Na}$ ture article received anti-PD-1/PD-L1 antibody monotherapy.

\section{Current Evidence of Immunotherapy in NASH-HCC}

The reasonable interpretation of the current evidence supporting the effectiveness of immunotherapy in NASH-HCC is as follows. (1) Immune checkpoint inhibitors may not be effective against pure NASH-HCC. This can be attributed to the weakened immune response from $\mathrm{CD}^{+} \mathrm{T}$ cells against tumor antigens and to defi- cient immune surveillance mechanisms. (2) Although the Nature study discussed here explored this topic from various angles, it did not examine the effectiveness of combination immunotherapy. The authors performed a meta-analysis using IMbrave 150 and CheckMate 459 data, however, the analysis included HCC of all non-viral etiology, therefore, the outcome of "pure NASH-HCC" with immunotherapy is unclear. This question should be investigated in future research. (3) It is not feasible to definitively diagnose NASH-HCC in clinical practice without histological examination; thus, it is possible that not all cases of clinically diagnosed NASH-HCC are pure NASH-HCC. (4) Not treating NASH-HCC diagnosed from clinical findings alone with atezolizumab plus bevacizumab may put patients at a disadvantage. Therefore, it is important to start treatment with atezolizumab plus bevacizumab and then promptly switch to second-line therapy if the first-line therapy is ineffective. In other words, when starting combination immunotherapy, it is extremely important to keep in mind the HCC etiology and the possibility that combination immunotherapy may not be effective for NAFLD-related HCC, as well as a quick switch to second-line therapy when progressive disease is observed early in NAFLD-related HCC.

\section{Statement of Ethics}

Not applicable to this work.

\section{Conflict of Interest Statement}

Lecturing: Eisai, Bayer, MSD, BMS, EA Pharma, Eli Lilly, Chugai. Grants: Eisai, Takeda, Otsuka, Taiho, EA Pharma, Gilead Sciences, Abbvie, Sumitomo Dainippon Pharma, Chugai, Ono Pharma. Advisory consulting: Eisai, Ono, MSD, BMS, Roche. M. Kudo is Editor-in-Chief of Liver Cancer.

\section{Funding Sources}

No funding was received for this work.

\section{Author Contributions}

M. Kudo conceived, wrote, and approved the final manuscript. 


\section{References}

1 Pfister D, Núñez NG, Pinyol R, Govaere O, Pinter M, Szydlowska M, et al. NASH limits anti-tumour surveillance in immunotherapytreated HCC. Nature. 2021 Apr;592(7854):450-6.

2 Dunn GP, Bruce AT, Ikeda H, Old LJ, Schreiber RD. Cancer immunoediting: from immunosurveillance to tumor escape. Nat Immunol. 2002 Nov;3(11):991-8.

3 Inada Y, Mizukoshi E, Seike T, Tamai T, Iida N, Kitahara M, et al. Characteristics of immune response to tumor-associated antigens and immune cell profile in patients with hepatocellular carcinoma. Hepatology. 2019 Feb;69(2):653-65.

4 Yau T, Park JW, Finn RS, Cheng AL, Mathurin P, Edeline J, et al. CheckMate 459: a randomized, multi-center phase III study of nivolum$\mathrm{ab}$ vs. sorafenib as first-line treatment in patients with advanced hepatocellular carcinoma. Ann Oncol. 2019;30 suppl 5:v874-5.

5 Finn RS, Ryoo BY, Merle P, Kudo M, Bouattour M, Lim HY, et al.; KEYNOTE-240 investigators. Pembrolizumab As Second-Line Therapy in Patients With Advanced Hepatocellular Carcinoma in KEYNOTE-240: A Randomized, Double-Blind, Phase III Trial. J Clin Oncol. 2020 Jan;38(3):193-202.

6 Finn RS, Qin S, Ikeda M, Galle PR, Ducreux M, Kim TY, et al.; IMbrave150 Investigators. Atezolizumab plus Bevacizumab in Unresectable Hepatocellular Carcinoma. N Engl J Med. 2020 May;382(20):1894-905.
7 Huang DQ, El-Serag HB, Loomba R. Global epidemiology of NAFLD-related HCC: trends, predictions, risk factors and prevention. Nat Rev Gastroenterol Hepatol. 2021 Apr;18(4):223-38.

8 Wolf MJ, Adili A, Piotrowitz K, Abdullah Z, Boege Y, Stemmer K, et al. Metabolic activation of intrahepatic CD8+ T cells and NKT cells causes nonalcoholic steatohepatitis and liver cancer via cross-talk with hepatocytes. Cancer Cell. 2014 Oct;26(4):549-64.

9 Dudek M, Pfister D, Donakonda S, Filpe P, Schneider A, Laschinger M, et al. Auto-aggressive CXCR6+ CD8 T cells cause liver immune pathology in NASH. Nature. 2021 Apr;592(7854):444-9.

10 Geh D, Anstee QM, Reeves HL. NAFLD-associated HCC: progress and Opportunities. J Hepatocell Carcinoma. 2021 Apr;8:223-39.

11 Kutlu O, Kaleli HN, Ozer E. Molecular pathogenesis of nonalcoholic steatohepatitis(NASH-) related hepatocellular carcinoma. Can J Gastroenterol Hepatol. 2018 Aug;2018:8543763.

12 Ramai D, Tai W, Rivera M, Facciorusso A, Tartaglia N, Pacilli M, et al. Natural progression of non-alcoholic steatohepatitis to hepatocellular carcinoma. Biomedicines. 2021 Feb;9(2):9.

13 Nahon P, Allaire M, Nault JC, Paradis V. Characterizing the mechanism behind the progression of NAFLD to hepatocellular carcinoma. Hepat Oncol. 2020 Dec;7(4):HEP36.
14 Kudo M. Hepatocellular carcinoma and NASH. J Gastroenterol. 2004;39(4):409-11.

15 Dyson J, Jaques B, Chattopadyhay D, Lochan R, Graham J, Das D, et al. Hepatocellular cancer: the impact of obesity, type 2 diabetes and a multidisciplinary team. J Hepatol. 2014 Jan;60(1):110-7.

16 Mittal S, El-Serag HB, Sada YH, Kanwal F, Duan Z, Temple S, May SB, Kramer JR, Richardson PA, Davila JA: Hepatocellular carcinoma in the absence of cirrhosis in United States veterans is associated with nonalcoholic fatty liver disease. Clin Gastroenterol Hepatol. 2016;14:124-31.e1.

17 Piscaglia F, Svegliati-Baroni G, Barchetti A, Pecorelli A, Marinelli S, Tiribelli C, et al.; HCC-NAFLD Italian Study Group. Clinical patterns of hepatocellular carcinoma in nonalcoholic fatty liver disease: A multicenter prospective study. Hepatology. 2016 Mar;63(3):827-38.

18 Stine JG, Wentworth BJ, Zimmet A, Rinella ME, Loomba R, Caldwell SH, et al. Systematic review with meta-analysis: risk of hepatocellular carcinoma in non-alcoholic steatohepatitis without cirrhosis compared to other liver diseases. Aliment Pharmacol Ther. 2018 Oct;48(7):696-703.

19 Sanyal A, Poklepovic A, Moyneur E, Barghout V. Population-based risk factors and resource utilization for HCC: US perspective. Curr Med Res Opin. 2010 Sep;26(9):2183-91.

20 Abbas AK, et al. Basic immunology: functions and disorders of the immune system. 4th ed. Philadelphia: Saunders; 2014. 